\title{
Akıllı Ev Teknolojisi için Kablosuz Akıllı Kit
}

\author{
Melih Kuncan $^{1 *}$, Ömer Çaça ${ }^{2}$ \\ ${ }^{1}$ Siirt Üniversitesi, Mühendislik Fakültesi, Elektrik-Elektronik Mühendisliği, Siirt, Türkiye (ORCID: 0000-0002-9749-0418) \\ ${ }^{2}$ Siirt Üniversitesi, Mühendislik Fakültesi, Elektrik-Elektronik Mühendisliği, Siirt, Türkiye (ORCID: 0000-0002-2608-8245)
}

(İlk Geliş Tarihi 16 Ağustos 2019 ve Kabul Tarihi 21 Ekim 2019)

(DOI: 10.31590/ejosat.605709)

ATIF/REFERENCE: Kuncan, M. \& Çaça, Ö. (2019). Akıllı Ev Teknolojisi için Kablosuz Akı1lı Kit. Avrupa Bilim ve Teknoloji Dergisi, (17), 271-282.

\section{$\ddot{O} z$}

Akıllı ev teknolojisi, son zamanlarda özellikle enerji tasarrufunun sağlanması, geniş güvenlik önlemlerinin alınması, yaşam konforunun arttırılması vb. birçok avantajlarından dolayı yaygın olarak kullanılmaktadır. Bu çalışmada akıllı ev otomasyon teknolojisinin mevcut yapılara daha ekonomik ve daha hızlı kurulabilmesi için, kablosuz olarak geliştirilen ve sistemin kontrolünün android tabanlı cep telefonu ile sağlanarak, santral üzerinden kumanda edilen kablosuz akıllı kitler tasarlanmıştır. Geliştirilen kablosuz akıllı kitler, android tabanlı cep telefonu üzerinden santrale gönderilen veriye bağlı olarak santral tarafindan kumanda edilmektedir. Mevcut yapıda kontrol edilmek istenen priz ve aydınlatmalara kablosuz akıllı kitler monte edilmektedir. Cep telefonundan gönderilen komuta bağlı olarak aydınlatma sistemi ve prizler devreye alınmakta, devreden çıkarılmaktadır. Aynı zamanda geliştirilen sistem hibrit bir sistem olup kablosuz sistemlerde (çamaşır makinesi, buzdolabı, aydınlatmalar, klima vb.) santrale doğrudan bağlanarak cep telefonu üzerinden kumanda edilmektedir. Sistemde bulunan keypet ile doğru şifrenin girilmesi durumunda dış kapının açılması ve cep telefonu üzerinden devreye alınan alarm sisteminin herhangi bir hareket durumunda ikaz vermesi geliştirilen akıllı ev otomasyonunun bir diğer avantajı olarak dikkat çekmektedir. Bu çalışmada üretilen kablosuz akıllı kit ile mevcut bir enerji sistemini uzaktan android tabanlı bir cihazdan kontrol etmek mümkündür. Tasarlanan ver üretilen system, santral ve kablosuz akılll kitlerden oluşmaktadır. Kontrol edilmek istenen priz, aydınlatma vb. diğer sistemlere akıllı kitler monte edilmektedir. Bu akıllı kitler, santralden gelen bilgiye göre devreye girmekte veya devreden çıkarılmaktadır. Sistemin kontrolü ise android tabanlı mobil cihaz üzerinden sağlanmaktadır. Geliştirilen kablosuz akıllı kit hibrit özelliğe sahip olup hem kablolu sistemlerde hem de kablosuz olarak evimizdeki cihazları kontrol edebilme yeteneğine sahiptir. Prototip olarak üretilen kablosuz akıllı kit mevcut bir yapı içinde bulunan aydınlatma ve priz hatlarına takılarak test edilmiştir. Test sonuçlarına göre $150 \mathrm{~m}^{2}$ ile $200 \mathrm{~m}^{2}$ arasındaki bir evde kablosuz akıllı kit ile santral arasındaki veri iletimi sorunsuz olarak sağlanmaktadır. Açık alanda ise $150 \mathrm{~m}$ ile $200 \mathrm{~m}$ arasında bir çekim gücü ile veri iletimi sağlandığı yapılan testler sonucunda gözlnemişitr. Benzer şekilde sistemin hibrit olma özelliği ile kablolu sistemlere de entegre edilerek test edilmiştir. Her iki durumda da test sonuçları başarılı bir şekilde gerçekleştirilmiş olup kullanılır duruma getirilmiştir. Sistemde bulunan güvenlik sistemlerinden alarm sistemi de testlerden başarıyla geçmiştir. Bu çalışmada tasarlanan ve üretilen kablosuz akıllı kitin başta akıllı ev teknolojisi alanı olmak üzere birçok farklı alanda kullanılabiliceği öngörülmektedir.

Anahtar Kelimeler: Akı1lı ev, Kablosuz kit, Akıllı kit, Akıllı ev otomasyonu, Ak1llı ev teknolojisi.

\section{Wireless Smart Kit for Smart Home Technology}

\begin{abstract}
Smart home technology, especially in recent years to provide energy savings, taking wide security measures, increasing the comfort of life and so on. It is widely used because of its many advantages. In this study, wireless smart kits, which are developed wirelessly and controlled by the android based mobile phone, are designed to control the system in order to install the smart home automation technology to the existing structures more economical and faster. The developed wireless smart kits are controlled by the exchange
\end{abstract}

\footnotetext{
${ }^{1}$ Sorumlu Yazar: Siirt Üniversitesi, Elektrik-Elektronik Mühendisliği, Siirt, Türkiye (ORCID: 0000-0002-9749-0418), melihkuncan@siirt.edu.tr
} 
based on the data sent to the exchange via the android based mobile phone. Wireless smart kits are installed in the sockets and lighting to be controlled in the existing structure. Lighting system and sockets are activated and deactivated depending on the command sent from the mobile phone. At the same time, the developed system is a hybrid system and it is controlled directly by the mobile phone in wireless systems (washing machine, refrigerator, lighting, air conditioning, etc.). Another advantage of the smart home automation system is the opening of the external door when the correct password is entered with the keypet in the system and the alarm system activated via the mobile phone to warn in case of any movement. It is possible to control an existing energy system remotely from an android based device with the wireless smart kit produced in this study. Designed and produced, the system consists of switchboard and wireless smart kits. Sockets, lighting and so on. smart kits are installed in other systems. These smart kits are activated or deactivated according to the information received from the exchange. Control of the system is provided via android based mobile device. The developed wireless smart kit has a hybrid feature and is capable of controlling the devices in our home both in wired systems and wirelessly. The wireless smart kit, which is produced as a prototype, has been tested by plugging it into the lighting and socket lines in an existing structure. According to the test results, data transmission between wireless smart kit and switchboard is ensured without problems in a house of $150 \mathrm{~m}^{2}$ to $200 \mathrm{~m}^{2}$. In the open area, data transmission with a gravitational power of $150 \mathrm{~m}$ to $200 \mathrm{~m}$ was observed as a result of the tests performed. Similarly, it has been tested by being integrated to the cable systems with the hybrid feature of the system. In both cases the test results were successfully performed and made available. The alarm system, one of the security systems in the system, also passed the tests successfully. In this study, it is predicted that the wireless smart kit produced as a prototype can be used in many different fields, especially in the field of smart home technology.

Keywords: Smart home, Wireless kit, Smart kit, Smart home automation, Smart home technology.

\section{Giriş}

Akıllı ev sistemi, aydınlatma, 1sıtma gibi alet ve sistemlerin uzaktan izlenmesini ve yönetilmesini sağlamak için bir ağ ile birbirine bağlı cihazların kullanıldığı evler için kullanılan bir terimdir. Akıllı ev, ev sahiplerine konfor, güvenlik, enerji verimliliği (düşük işletme maliyeti) ve rahatlık sağlayan bir sistemdir. Akıllı ev, birbirleriyle iletişim kurabilen ve içinde birbirleriyle iletişim kurabilen aletleri, aydınlatma, ısıtma, klima, TV'ler, bilgisayarlar, eğlence ses ve video sistemleri, güvenlik ve kamera sistemlerini içeren bir konutu tanımlamak için yaygın kullanılan terimdir. Evdeki herhangi bir odadan dünyanın herhangi bir yerinden uzaktan telefon ya da internet aracılığıla bir zaman çizelgesi ile uzaktan kontrol edilebilir. Akıllı ürünlerin kurulması, eve ve ev sahiplerine çeşitli avantajlar sağlar. Teknoloji ve kişisel bilgisayar uygulamalarının bize, son 30 yılda kazandırdığı faydalar zaman, para ve enerjiden tasarruf sağlamasıdır. Sistem değişen bir ailenin ihtiyaçlarını karşılamak için zaman geçtikçe büyüyebilir. Bu ürünlerin tamamı, çeşitli üreticilerin arasından seçilebilir; pahalı bir eskime veya rekabetçi olmayan fiyatlandırma önlenir. Akıllı bir evin ortaya çıkan önemli bir özelliği, dünyanın sınırlı kaynaklarının korunmasıdır. Aydınlatma, elektrikli cihazlar, sulama kontrolü ve kullanım izleme yoluyla tasarruf artırmak için ev aletleri ile entegre ev denetleyicilerinden yararlanarak evlerini gerçekten akıllı hale getirebilme yeteneğinin giderek daha fazla insan tarafından farkına varılıyor. Çoğu ev denetleyicisi, bağlı tüm aygıtlar tarafından kullanımı hesaplar ve kaydeder, böylece ev sahibine gerekli değişiklikleri yapma bilgisi veren yerleşik izleme sistemlerine sahiptir. Bu sistemler internette dünyanın herhangi bir yerinden erişilebilir; böylece ev sahibi her zaman sistemi ayarlayabilir Akıllı ev, ev teknolojileri endüstrinin birçok alanında kullanılan kontrol sistemlerinin gündelik hayata uyarlanması; ev otomasyonu da, bu teknolojilerin kişiye özel ihtiyaç ve isteklerine uygulanmasıdır [1-3].

Akılı Ev fikri ilk olarak 1980’lerin basında ortaya çıkmıştır. İlk uygulamalarda, sıradan her hangi bir fiziksel engeli olmayan insanların ev konforu düşünülmüştü. Üreticiler, bir sistemi bütününü entegre etmeyi amaçlamamışlardı. Ancak, bireysel olarak kontrol edilebilecek birçok ürün çeşidi ortaya çıktı (enerji kontrol ünitesi, güvenlik sistemi, 1şık kontrolcüleri, v.s.). Günümüzde ise, ev teknolojileri, bizlerin hiç de yabancı olmadığı bir konu haline gelmiştir. Mikserler, kahve makineleri ve mutfak robotları, televizyonlar, müzik setleri, DVD oynatıcılar, videolar; buzdolapları, çamaşır ve bulaşık makineleri, otomatik garaj kapıları, 1şık seviyesi ayarlanabilir lambalar, telsiz telefonlar, elektrik süpürgeleri ve daha bunlar gibi birçok cihaz ile hayatımızın ayrılmaz bir parçası olmuştur. Daha sonraları bu cihazlar, yine gelişen teknolojiyle hayatlarımızı kolaylaştırmak için birçok değişim geçirdi; televizyonlar, müzik setleri ve hatta garaj kapıları için uzaktan kumandalar; kahve makineleri için zamanlayıcılar, kullanıcıya birçok seçenek sunan çamaşır ve bulaşık makineleri, buzdolapları geliştirildi. Bu sürecin bir sonraki adımı, tüm evin tek bir noktadan kontrol edilmesine imkân veren ve programlama imkânlarıyla bu kontrolü kendiliğinden sağlayan ev otomasyon teknolojilerini tüketicilerin hizmetine sunmaktadır. Akıllı ev sistemleri, bilgisayar ve iletişim sistemlerinin oldukça gelişmiş olması ile günümüzde yaygın olarak kullanılmaktadır. Özellikle veri iletiminin kablosuz olarak yapılması, kablolu iletişimin zorluklarından kaynaklanan problemleri ortadan kaldırmaktadır. Mevcut akıllı ev otomasyonlarının sisteme entegre edilmesi için kablolu alt yapı oluşturulmalıdır. Bu yeni yapılacak yapılarda sürecin başında ve yapının, alt yapıyı kurmaya müsait olmasıyla sağlanabilir. Ancak mevcut yapılarda bu alt yapıyı oluşturmak oldukça maliyetlidir [4-7].

Programlanmaya elverişli bir ev otomasyon sistemi, aşağıdaki örneklerde bahsedilen kontrollerden hepsini, daha fazlasını veya bazılarını gerçekleştirebilir.

> Sabah uyandığınızda, ayarladığınız saatte, panjurlarınız istediğiniz kadar açılabilir. Odalar istediğiniz sıcaklığa getirilir. Sabah çayınız, kahveniz, müziğiniz, haberleriniz istediğiniz saatte hazırlanabilir. Balkonunuzdaki veya bahçenizdeki tente güneş ışınlarına göre açılıp, rüzgâr şiddeti arttığında kapanır.

$>$ Biz yokken evimiz ayarladığınız sıcaklıkta kalır. İstersek telefon veya internet üzerinden sıcaklığı değiştirebiliriz. Biz dişarıdayken evimiz boşa enerji harcamaz.

$>$ Işık sensörü ile günesin batışı algılanır ve perdelerin kapanması, evde istediğiniz ışıkların açılması sağlanır. 
> Alarm harekete geçmişse, hareket sensörü ile güvenlik ışıklarının yanması ve alarmın tetiklenmesi sağlanır.

$>$ Uzun seyahatlerimizde panjur ve pencereler açılarak ev güneşlendirilir veya havalandırılır, bahçe sulama sistemi çalıştırılır, akşam belli saatlerde ışıkları yakılarak evde birilerinin olduğu izlenimi verilebilir.

> Biz evimizde değilken ya da uyurken alarm sistemleri kendiliğinden aktif konuma geçer ve evimiz koruma altına alınır. Hırsız girmesi durumunda kameralar kayıta geçer, alarm sistemi, ses ile ya da ışıkları açarak uyarır ve polis merkezini telefon ile arayarak otomatik mesaj gönderir. Yangın durumunda, evdeysek iç sirenle dışarıdaysak bizi telefonla arayarak uyarır, itfaiyeyi arar, gaz vanalarını ve havalandırma sistemini kapatır, belirli bölgelerde ışıkları yakarak evden çıkışımıza yardımcı olur.

$>$ Duman sensörü ile yangın algılanır ve alarm çalışır, bize telefonla bilgi verilir.

$>$ Geceleyin ışıklar bizim bulunduğunuz yerlerde otomatik olarak yakıllır olmadığınız bölgelerde ise söndürülür.

> Bahçedeki çimlerin yağmur durumuna göre, belirli aralıklarla sulanması sağlanır.

$>$ Tek bir komutla, perdeleri indirip, ışıkları kısıp, mısır patlatma makinesini çalıştırıp, telefonu sessiz konuma alıp DVD oynatıcısını ve Televizyonu açarak ev sinema keyfi yaşatır.

> Telefonla verilen komutlarla ev içinde mümkün olan tüm kontrolleri gerçekleştirir.

$>$ Çocuklar okuldan eve geldiğinde bizi telefonla arayıp haber verebilir.

D Evdeki cihazlar ve 1şıklar uzaktan kumandayla kontrol edilebilir.

$>$ Evdeki tüm lambaların ışık seviyesi ayarlanabilir.

> Günün belirli bir saatinde veya istenildiği anda bizi ya da çocuklarımızı uyandırır.

$>$ Çocukların televizyonunu her gün akşam belirli bir saatte kapatabilir.

$>$ Telefon çaldığında televizyon veya müzik setinin sesini kapatabilir.

$>$ Telsiz telefonumuzu evi tamamen kontrol edebilecek bir kumandaya dönüştürür. Hareketi kısıtlı kişiler, uzaktan kumandayla çevrelerini çok daha rahat kontrol edebilir ve gerektiğinde yardım çağırabilirler.

$>$ Şüpheli bir durumda evimizdeki iç ve dış tüm ışıklar tek düğme ile açılabilir.

> Çamaşır makinesi gibi fazla elektrik tüketen cihazların, akıllı sayaçlarla uyumlu olarak, indirimli saatlerde çalışması sağlanabilir.

> Lambaları tam parlaklıkları yerine daha düşük (\%90) parlaklıkta yakarak, ampullerin ömrünü arttırır ve de enerji tüketimlerini $\% 30$ oranında azaltır.

Bu çalışmada akıllı ev sistemlerinde kullanılabilecek Kablosuz akıllı kit geliştirilmiştir. Geliştirilen kablosuz akıllı kit ile veri iletimi, kablosuz iletişim modülleri kullanılarak gerçekleştirilmektedir. Böylelikle akıllı ev otomasyonuna geçecek yapılar için alt yapı oluşturulmayacak, bundan kaynaklanan tadilat ve dekorasyon masrafları da ortaya çıkmayacaktır. Ayrıca kablosuz akıllı kit oldukça ekonomik olarak tüketiciye ulaşmış olacaktır. Sistem kullanımı ve kurulumu bakımından oldukça kolay olup herkes tarafından mevcut siteme montajı yapılabilecektir. Kablosuz akıllı kitin özellikleri aşağıda sıralanmıştır [8-13].

- Ekonomik: Kablosuz akıllı kit ile Akıllı ev otomasyonunuz en az maliyet ile oluşturulur. Mevcut sistemlerdeki alt yapı masraflarını ortadan kaldırarak sistemi daha ucuz kullanmanıza olanak sağlar. Yalnızca ihtiyacınız kadar akıllı kit kullanarak sistemden tasarruf edebilirsiniz.

- Kablosuz iletişim: Kablosuz akıllı kit, mevcut yapınızda herhangi bir alt yapıya gereksinim duymadan kurulabilir. Sistem kendi arasındaki veri iletimini tamamen kablosuz olarak wireless modülleri ile sağlamaktadır.

- Hızlı Kurulum: Kablosuz akıllı kitler, portatif olarak yapıldığından yalnızca aydınlatma ve prizlere kullanıcı tarafından ara eleman olarak takılmaktadır. Bu özelliği ile kolay ve hızlı bir şekilde kurulup sisteme entegre edilebilmektedir.

- Enerji tasarrufu: Kablosuz akıllı kit ile günlük yaşantımızda, evimizde, ofisimizde gereksiz yere tüketilen enerjiden tasarruf sağlanmaktadır. Sağlanan bu enerji tasarrufu sayesinde küresel ısınma, sera etkisi ve kaynak kullanımı azaltılarak refah seviyesi arttırılmış olur.

- Güvenlik seviyesinin arttırılması: Evimizde veya ofisimizde kurulu olan güvenlik sisteminin takibi, her noktadan kolaylıkla yapılıp gerekli önlemler anlık olarak yapılmaktadır. Evimizde olmadığımız zamanlarda evdeki ş̧ıklar, perde ve panjur sistemi uzaktan kontrol ederek evdeymiş hissi verebilir. Bu şekilde ev, ofis, endüstriyel tesis için dış tehlikelere karşı üst düzey bir koruma sağlamış olunur.

- Yaşam standartının artııılması: Gelişen teknoloji sayesinde günlük yaşamımızın her anında neredeyse ihtiyaçlarımızın tamamını akıllı cihazlarla gidermekteyiz. Bu durum toplum için yaşam standartlarının arttırılması ve akıllı cihazların giderek hayatımızın bir parçası haline gelmesine olanak sağlamaktadır.

Mevcut akıllı ev otomasyonlarından kablosuz olma özelliğiyle ayrılan sistemde aynı zamanda alarm sistemi ve giriş kapısının şifreyle açma özelliği bulunmaktadır. Cep telefonundan gönderilen komut bilgisi santral üzerinde bulunan ekran aracılığıyla kullanıcıya anlık olarak aktarılmaktadır. Bu çalışma sayesinde mevcut yapılara akıllı ev otomasyonunu, en az maliyet ile entegre ederek talebin artacağı düşünülmektedir. Benzer şekilde enerji israfının, kablosuz akıllı kitin sisteme entegre edilmesi ile önleneceği bir diğer avantaj olarak düşünülmektedir.

\section{Sistemin Çalışma Prensibi}

Çalışma kapsamında geliştirilen kablosuz akıllı kitler, Android yazııım sistemine uygun Arduino Mega ADK, Android yazılım tabanlı cep telefonu ve kablosuz iletişim modülleri ile birlikte çalışan Arduino UNO modeli kullanılarak tasarlanmıştır. İstenilen 
algoritmanın gerçekleşmesi için Arduino’dan yararlanılarak kablosuz akıllı kitler programlanmış ve çalışması düzenlenmiştir. Arduino Mega ADK'nın programlanması Arduino kitine ait Arduino IDE yazılım programıla ve cep telefonu Android uygulamasını yapmak için de MIT AP İNVERTER kullanılarak sistem programlanması sağlanmıştır. Sistem basitçe santral ve kablosuz akıllı kitlerden oluşmaktadır. Kontrol etmek istediğimiz priz veya aydınlatmaya akıllı kitler takılmaktadır. Bu akıllı kitler santralden gelen bilgiye göre devreye girip veya devreden çıkarılmaktadır. Sistemin kontrolü ise android tabanlı mobil cihaz üzerinden sağlanmaktadır. Bu çalışmanın temel çalışma prensibi kablosuz olarak çalışması olsa da temelde farklı elemanların bir araya gelmesiyle çalışan bir sistem bulunmaktadır.. Şekil 1'de tasarlanan sisteme ait blok diyagram verilmiştir.

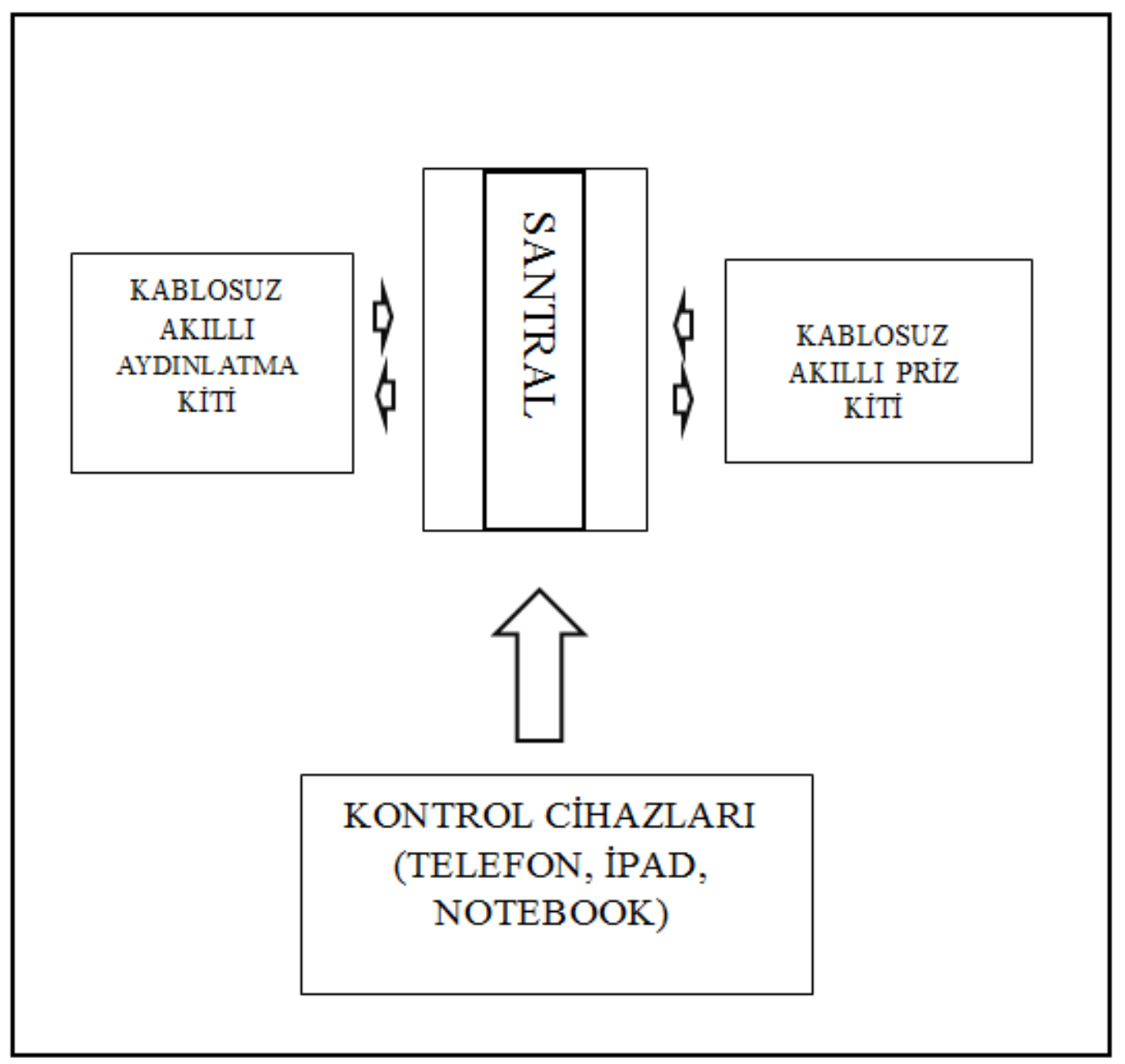

Şekil 1. Sistemin genel çalışma prensibine ait blok diyagram

Sistemin tüm süreci santral tarafından yürütülmektedir. Sisteme entegre edilen kablosuz kitler santral ile veri alışverişi sağlamaktadırlar. Benzer şekilde akıllı ev otomasyonunun kontrol elemanları (Tablet, PC, Telefon, İpad vb.) santral üzerinden sisteme bağlanır. Kontrol cihazı ile santral arasında ki iletişim bluetooth modülü üzerinden sağlandığı gibi santal ile kablosuz akıllı kitler arasındaki veri alışverişi wireless modülleri kullanılarak gerçekleştirilmiştir. Santrale entegre edilen wireless modülü verici görevi görmektedir. Sistemde her ne kadar kablosuz akıllı kitler ön planda olsa da santral üzerinde bulunan röle sistemleri sayesinde kablolu alt yapıya sahip olan yapılara da entegre edilebilir. Altyapısı mevcut olan yapıların santral ile elektriksel bağlantılarının yapılması durumunda kontrol cihazından kablolu sistemlerin de kontrolü sağlanabilmektedir. Şekil 2'de santral sistemine ait blok diagram gösterilmiştir. 


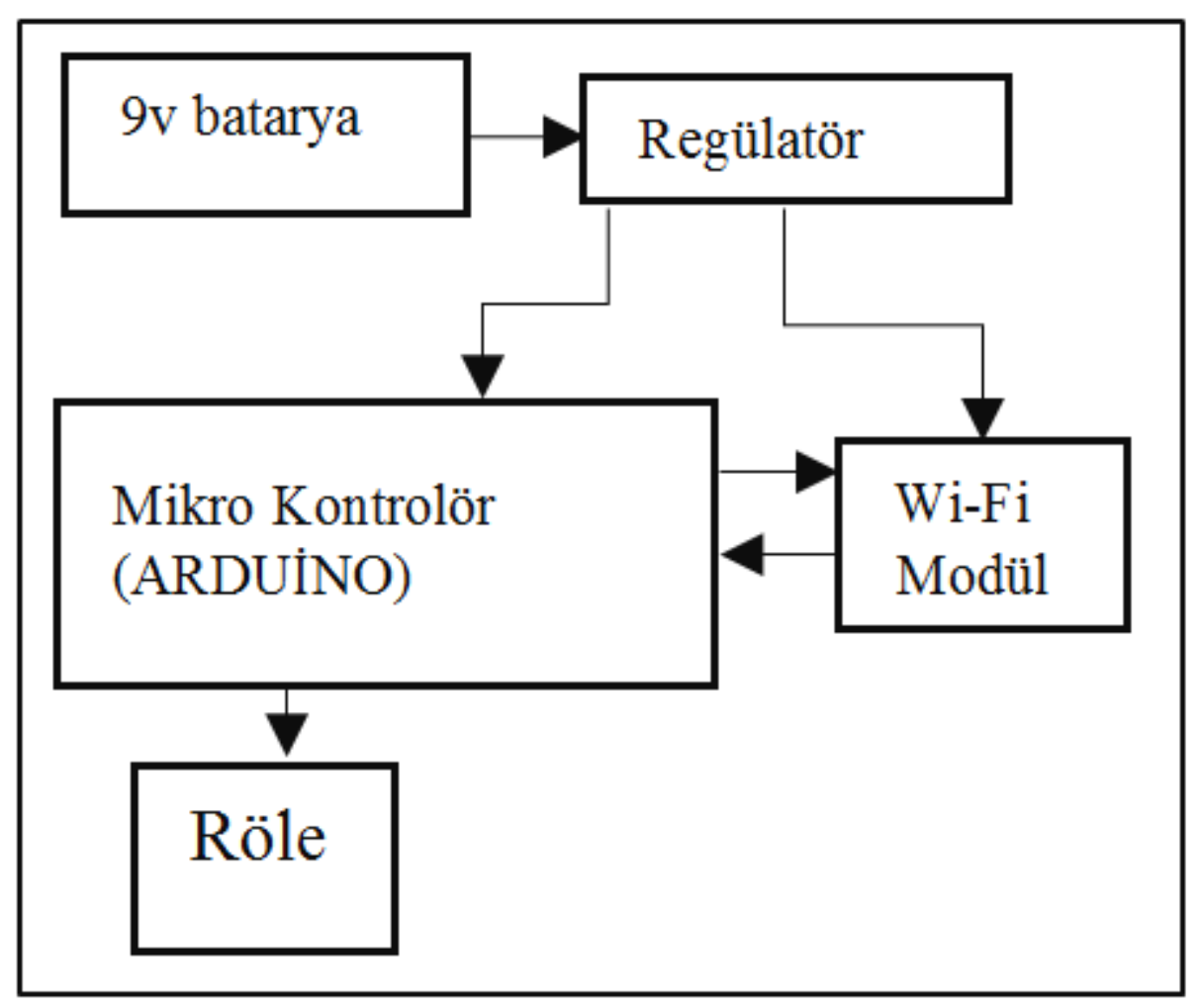

Şekil 2. Kablosuz akillı kit blok diyagramı

Görüldüğü gibi şekil 2' de sistem de bulunan kablosuz akıllı kite ait blok diyagram verilmiştir. Santral iç tasarımı blok diyagramda bulunan elemanlar ile gerçekleştiririlmiş olup birim elemanların bir araya getirilmesiyle gömülü bir sistem ortaya çıkarılmıştır. Santralde mikro denetleyici olarak Arduino Mega 2560 ADK kullanılmıştır. Sisteme ilişkin yazılım Arduino dili kullanılarak programlanmıştır. Santral içinde bulunan tüm elemanların santral ile doğrudan bağlantısı yapılıp tasarlanmıştır. Santral içinde bulunan Wi-Fi modülü nrf24L01 ile sisteme entegre edilmiş olup santralde verici görevini üstlenmektedir. Kablosuz akı1lı kitler ile iletişim nrf24L01 üzerinden sağlanmaktadır. Bluetooth modülü ise kontrol cihazı ile olan iletişimi sağlamak için HC-06 modülü kullanılarak sisteme entegre edilmiştir. Santralde bulunan röleler, santralin kablolu sistemlere de kolaylıkla entegre edilebilmesi için santrale dahil edilmiştir. Santral üzerinde bulunan keyped çıkışı dış kapıya bağlanan keypetten gelen şifre bilgisinin santrale aktarıldığı giriştir. Benzer şekilde alarm sensör çıkışı, pır sensörden alarm sistemi için gelen sinyallerin santrale aktarıldığı giriştir. Buzzer ise yazılmış olan yazılıma bağlı olarak alarm ikazında devreye girerek kullanıcıları haberdar etmektedir. Bunun yanı sıra santral üzerinden bulunan butonlardan biri sistemi resetlemeye yararken diğer buton alarm sisteminin ikaz vermesi durumunda kullanıcıların kontrolünde alarm sisteminin devreden çıkarılması için bulunmaktadır. Sistemde kontrol cihazı üzerinden gelen bilgilere bağlı olarak aktif edilen sistemlerin devrede olduğunu gösteren LED ışıklar bulunmaktadır. Tüm bu sistemlerin yanında kontrol cihazından gönderilen tüm komutlar ve santral çalışma durumu anlık olarak LCD ekran üzerinden kullanıcılarla paylaşılmaktadır. Santral ise enerji ihtiyacını 12w lık bir DC adaptör üzerinden karşılamaktadır.

Kablosuz akıllı kitler tasarlanan sistemde kablosuz iletişimin en önemli sonuçları olarak görülebilir. Kablosuz akıllı kitler temel olarak Android tabanlı kontrol cihazından (Tablet, İpad vb.) santrale gönderilen komuta göre santral tarafindan kontrol edilerek bağlı bulunduğu sistemi devreye alıyor veya devre dışı bırakıyor. Tasarlanan kitler temel olarak; Kablosuz akıllı aydınlatma kiti ve kablosuz akıllı priz kiti olmak üzere ikiye ayrılmaktadır. İki farklı kit tasarlanması, aydınlatma ve priz hattına bağlanacak yükler arasında yüksek oranda farklı1ıklar olması göz önüne alınarak gerçekleştirilmiştir. Kablosuz akıllı aydınlatma kitleri, kablosuz akıllı priz kitlerine göre daha az güç taşıyabilecek donanımlarla oluşturulup ekstra maliyetin önüne geçilmiştir. Kablosuz akıllı kitler kontrol edilmek istenen aydınlatma ve prizlere takılmaktadır. Örneğin; evimizde yalnızca birkaç aydınlatma grubunu veya birkaç elektrikli cihazı (Çamaşır makinesi, televizyon, ssıtıcılar, klima vb.) kontrol etmek istiyorsak sadece bu aydınlatmaların veya cihazların enerji almış olduğu noktalara (Priz veya avize) kablosuz akıllı kitlerin takılması yeterli olacaktır. Kablosuz akıllı kitlerin bu özelliği sistemin kullanılabilirliğini arttırıp sistemden tasarruf etmemizi sağlamaktadır. Kablosuz akıllı aydınlatma ve priz kitine ilişkin blok diyagram aşağıda Şekil 3'te gösterilmektedir. Şekil 3'te gösterildiği gibi kablosuz akı1lı priz kiti temel olarak bir mikro kontrolör tarafından sistem akışı sağlanmaktadır. Kablosuz akıllı kitte bulunan mikro kontrolör yerine arduino UNO R3 kartı kullanılmıştır. Kit içinde bulunan Wireless modülü ise santral sisteminde kullanılan nrf24L01 modülü ile veri iletimini sağlayabilmesi için burada da nrf24L01 kablosuz iletişim modülü kullanılmıştır. Kablosuz akıllı priz kiti sahip olduğu wireless modülü santrale alıcı olarak tanıtılmıştır. Kontrol cihazı üzerinden kitin devreye girmesine ilişsin bir sinyal santrale gönderildiğinde, santral yalnızca belirlenen kitin alabileceği bir mesaj göndermektedir. Yani örneğin priz 1 açılsın komutu kontrol cihazından santrale gönderildiğini varsayalım. Santral ise içinde bulunan yazılıma bağlı olarak sadece prizl kitinin alabileceği üç haneli bir şifre göndermektedir. Alıcı olarak sisteme entegre edilen priz 1 kiti gelen şifrenin kendisine kaydedilen şifre ile uyumlu olması durumunda yapılacak işlem komutunu algılayıp aktif veya pasif olmaktadır. Her aydınlatma ve prizin santralden aldığ bir şifresi bulunmaktadır. Bu durumda priz 1 çalıştırılmak istenirken gönderilen komut priz 2 alıcısı tarafından algılanıp devreye girmemektedir. Ancak ve ancak alıcı kitlerde 
yazılımsal olarak belirtilen kendilerine özgü şifre doğruluğu teyit edildikten sonra alıcı kit kontrol edilebilir. Sisteme entegre etmiş olduğumuz wireless modülü sayesinde tek bir santrale 126 adet kablosuz akıllı aydınlatma ve priz kiti entegre edilebilmektedir. Wireless modülü açık alanda 150-175 m arasında bir çekim gücüne sahipken kapalı alanda $25-30 \mathrm{~m}$ aralığında aktif olarak çalışmaktadır. Arduino UNO R3 kartında bulunan yazılım tamamen santralle bir bütün olacak şekilde yazılmış olup sisteme özgü tasarlanmıştır. Portatif olarak tasarlanan akıllı kitler kullanılmaması durumda üzerindeki buton aracılığıyla kapatılabilir ve sistemden devre dışı bırakılabilir. Kablosuz akıllı kitler enerji ihtiyacını ise içinde bulunan 9V luk bataryalardan karşılamaktadır. Kullanılmaması durumunda kit üzerinde bulunan kapama düğmesi aracılı̆̆ıla kapatılıp daha uzun ömürlü kullanımlar sağlanabilir.

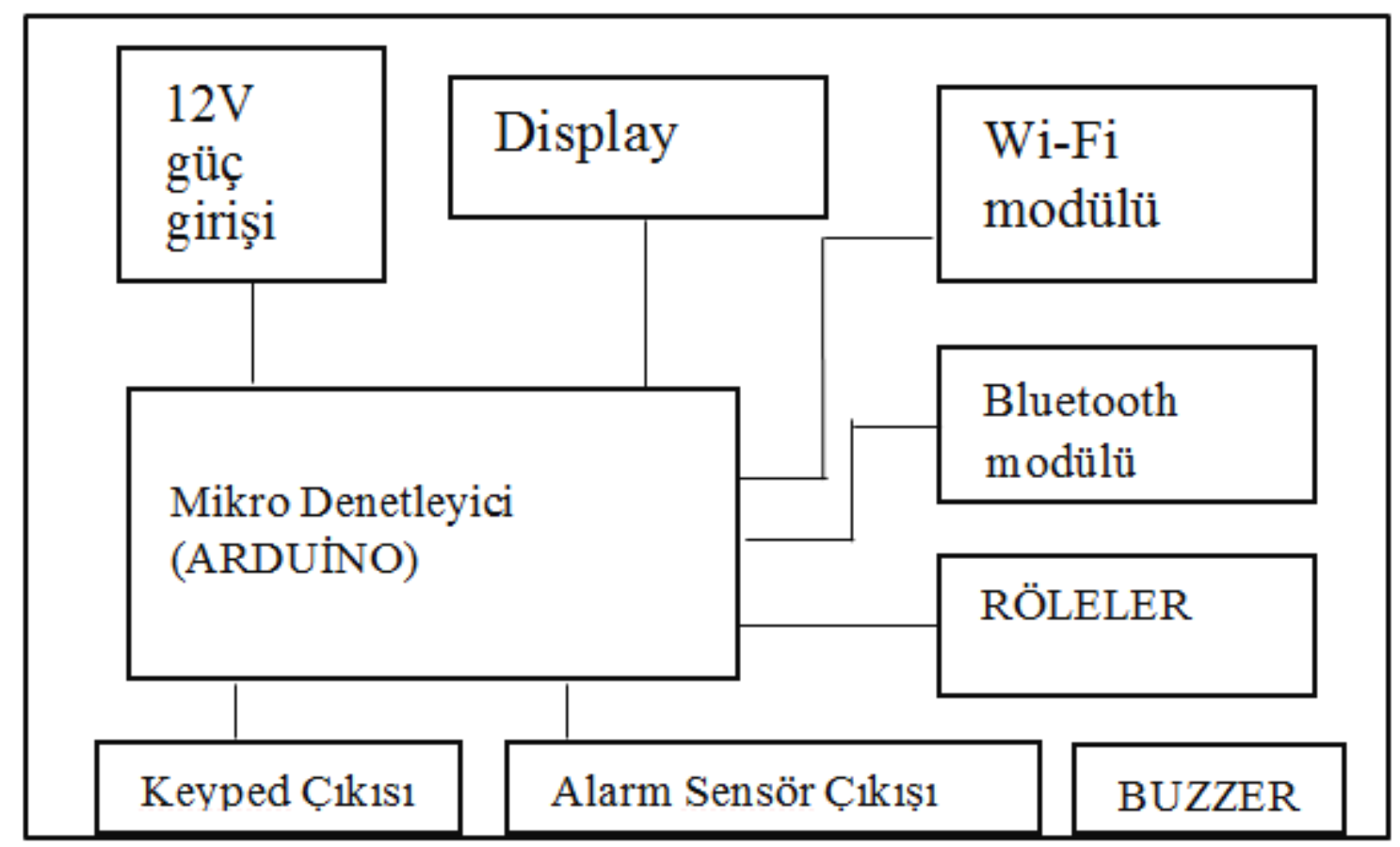

Şekil 3. Santral blok diyagram

\section{Kontrol Mekanizması}

Günümüzde kablosuz iletişim sistemlerinin bu denli gelişmesi sistemler üzerindeki kontrolü oldukça kolaylaştırmaktadır. Herhangi bir noktadan içinde bulunduğumuz kablosuz ağ sistemine bağlanarak dünyanın diğer ucundaki cihaz kontrol edebiliriz. Benzer şekilde ağ sisteminin bulunmadığı noktalarda bluetooth teknolojisi yardımıyla kablosuz olarak herhangi bir cihaza kontrol verisi gönderilebilir. Geliştirmiş olduğumuz sistemde santrale gönderilen veri android tabanlı bir cihazdan (tablet, ipad vb.) sağlanmaktadır. Veri iletimi ise Bluetooth modülü üzerinden gerçekleştirilmektedir. Kontrol cihazının, sisteme entegre edilen kitleri aktif veya pasif yapmasını sağlayacak verileri santrale göndermesi gerekmektedir. Bunun için android tabanlı bir uygulama geliştirilmiş̧ir. Geliştirlen uygulamaya AKILLI EV MEGA adı verilmiştir. Uygulama web araçlarından MIT AP İnvertor üzerinden oluşturulmuştur. Uygulama tamamen sisteme özgü tasarlanmış olup sistem bütünlüğünü oluşturmaktadır. Şekil 4 'te android uygulamaya ait bir görsel bulunmaktadır. Uygulamaya ilk giriş yapıldı̆̆ı anda bize herhangi bir Bluetooth aygıtı ile bağlantısının olmadığı bilgisini vermektedir. "BAĞLANTI YOK" yazısının hemen altında 'Bluetooth Aygıtını Seç" seçeneği bulunmaktadır. Bu metin kutusuna tıklandığında karşımıza gelen HC-06 Bluetooth aygıtı seçilmektedir. Tabi bu aygıtın uygulamayı kullanmadan önce HC-06 ile eşleştirilmiş olup "1234" şifresinin (tanımlananan hernangi bir şifrenin) girilmiş olması gerekmektedir. Seçilen Bluetooth aygıtı ile "BAĞLANTI YOK" metin kutusu bağlantının kurulduğunu göstermek için "BAĞLANDI" şeklinde değişmektedir. Uygulama da temel olarak yapılması istenen komutlar kendi isimleriyle yazılmıştır. Ancak arka planda veriler, santrale karakter olarak gönderilmektedir. Örneğin uygulama üzerinde "LAMBA 1 AÇIK " butonuna tıklanması durumunda uygulama tarafindan santrale 'C' karakteri gönderilmektedir. Santralde ise ' $\mathrm{C}$ ' karakterinin gelmesine ilişkin koşul sağlanıp istenen komut yerine getiriliyor. $\mathrm{Bu}$ durumda LAMBA 1 açılıyor. Benzer şekilde tam tersi durumda da geçerlidir. "LAMBA 1 KAPAT" butonuna basılması durumunda santrale "J" karakteri gönderiliyor. Santralde 'J' karakterine ilişkin koşul sağlandığında gerekli komut satırları gerçekleştiriliyor. Uygulama kullanımı açısından oldukça açık ve herkes tarafından rahatlıkla kullanılabilecek şekilde tasarlanmıştır. Uygulama üzerinden akıllı ev otomasyonuna bağlı tüm kablosuz akıllı kitler ve kablolu sistemler aynı anda devre dışı bırakılabilmektedir. Alarm sistemi devreye alınıp iklimlendirme sistemleri kumanda edilebilmektedir. 


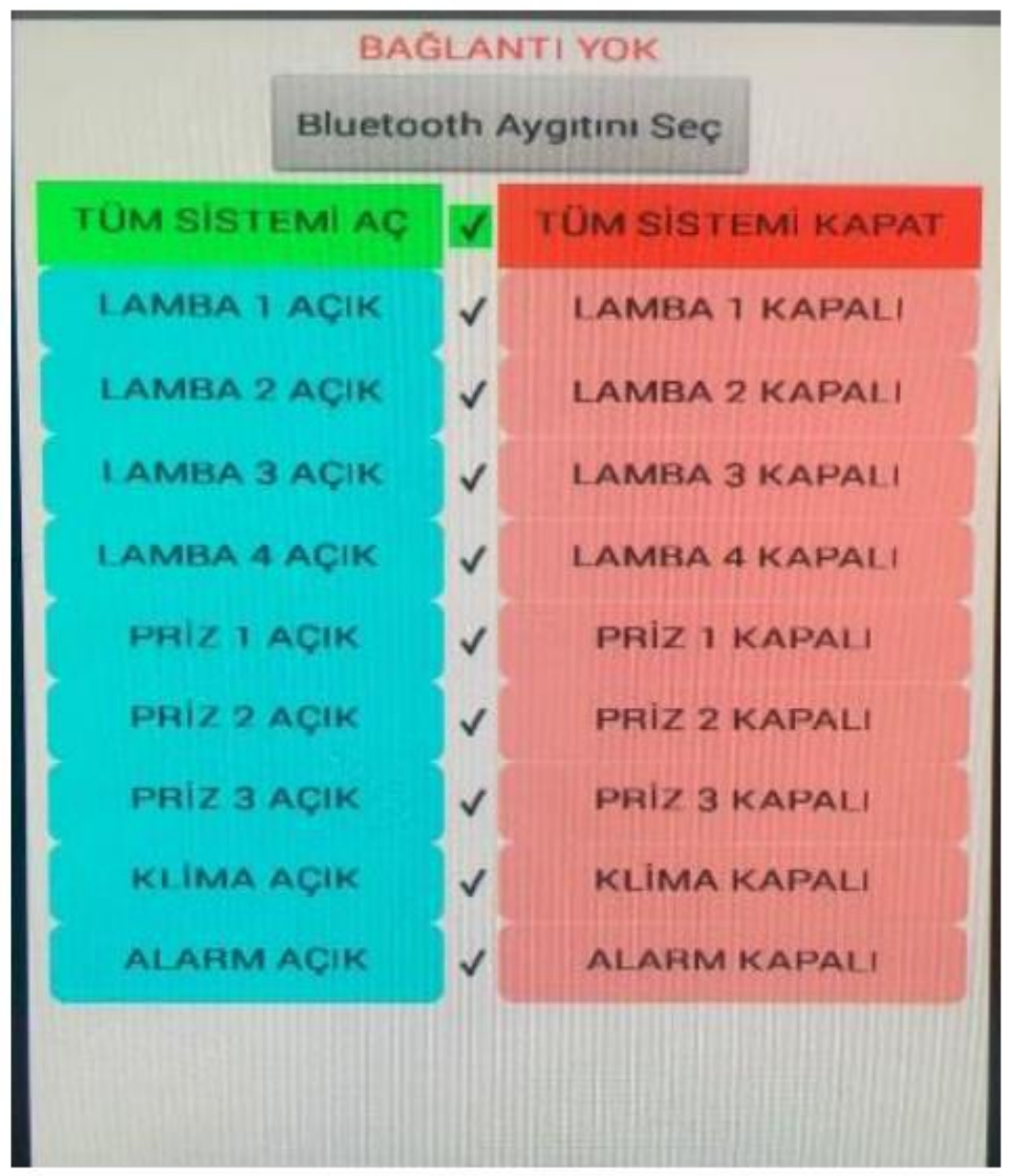

Şekil 4. Android uygulamaya ait tasartm

\section{Kablosuz Akıllı Kitin Tasarımı, İmalatı ve Programlanması}

Geliştirilen kablosuz akıllı kit (akıllı ev otomasyonu) hibrit özelliğe sahip olup hem kablolu sistemlerde hem de kablosuz olarak evimizdeki cihazları kontrol edebilme yeteneğine sahiptir. Kablosuz akıllı kitin şimdiye kadar bahsettiğimiz fonksiyonlarının yanı sıra eklenmesi planlanan birçok sistem mevcuttur. İlerleyen aşamalarda kablosuz akıllı kitlerin yalnızca kontrol cihazı üzerinden değil de priz kitlerinin kendi üzerinde bulunan bir buton veya aydınlatma kitlerinin aydınlatma anahtarından kontrol edilebilme özelliği sisteme entegre edilebilir. Benzer şekilde daha önceden evinizde kullanmış olduğunuz akıllı ev otomasyonunun arızası durumunda farklı bir ürün olarak kendi sisteminize entegre edilebilir özelliği eklenebilir. Sistem kontrolü, Bluetooth modülü üzerinden yapılabildiği gibi sistemin bağlı olduğu Wi-Fi üzerinden de yapılabilir. Bu durumda sistem kontrolü için yalnızca evin sınırlarında kalmayıp dünyanın her yerinden internet ağı yardımıyla sistem kontrolünü sağlayabilirsiniz. Santral üzerinde yapılan tüm işlem bilgisi anlık olarak LCD ekran üzerinden kullanıcı ile paylaşıldığı gibi kontrol cihazına da durum bilgisi anlık olarak aktarılabilir. Tüm bunların yanında sistemin kurulduğu yapının güvenlik sistemi elemanları kablosuz olarak tasarlanıp sinyaller kablosuz olarak santrale aktarılabilir. Bahçe sulama sistemi, yangın sistemi gibi sitemler akıllı ev otomasyonu bünyesine katılıp geliştirilebilir. Tüm bunların yanında akıllı ev otomasyonuna kişisel olarak hazırladığınız senaryolarınızı kaydedebilir, evinizde olmadığınız zamanlarda evdeymiş hissi vererek dış tehditlere karşı koruma sağlayabilirsiniz. Tasarlanan prototipler daha da küçültülüp kullanılabilirlik ve estetik tasarımı iyileştirilebilir. Akıllı ev otomasyonuna ait görsel Şekli 5'te ve Akıllı kitin çalışma mantığına ait görsel Şekil 6'da verilmiştir.

Santral ve kablosuz akıllı kitlerde bulunan mikro denetleyiciler yerine Arduino kartı kullanılarak programlanmıştır. Santralde bulunan arduino (MikroDenetleyici) ise bluetooth üzerinden gelen veriye bağlı olarak uygun kitlerin devreye alınıp ve devreden çıkarılmasını sağlayacak şekilde programlanmıştır. Santralde bulunan program standart arduino kütüphaneleri ve örnek çalışmalar dikkate alınarak sisteme özgü olarak gerçekleştirilmiştir. Benzer sekilde akıllı priz ve aydınlatma kitleri içinde bulunan program, santralden gelen veriyi alıp röleleri enerjileyerek bağlı bulunduğu sistemi (lamba, avize, çamaşır makinesi, buzdolabı, klima vb.) devreye alıp devreden çıkaracak şekilde yazılmıştır. Kontrol cihazı, santral ve kablosuz akıllı kitler ayrı ayrı gerçekleştirilen yazılımlar sayesinde bir bütün olarak tasarlanmıştır. Sistemin program akışı temel olarak üç kısımdan oluşmaktadır. Birinci kısımda arduinoya bağlanan modül ve cihazların arduino bünyesinde oluşturulan standart kütüphaneleri, karakter, dizi ve değişkenlerin tanımlandığı kısımdır. İkinci kısım ise Arduino üzerinde bulunan analog ve dijital pinlerin hangi modda çalıştırılacağı ve pinlerin isimlerdirmelerinin yapıldığı kısım olmakla birlikte kart üzerindeki tüm pinlerin ilk başlangıç durumunun belirtildiği kısımdır. Son 
olarak üçüncü kısım ise asıl algoritmaların yer aldığı ve if, while, for gibi komutların işlendiği kısımdır. Program başlangıcında belirtilen değişkenler üçüncü kısımda belirtilen koşullarda kullanılarak yapılması istenen durum oluşturulur. Sistemde bulunan santrale bağlı nrfL01 modülü hem alıcı hemde verici olarak programlanabilmektedir. Bu durumda kullanılmış olduğu sistemde hem veri alıp hemde veri gönderebilmektedir. Santral üzerindeki nrf24101 modülü verici olarak programlanmıștır. Kablouz akıllı kitlerde bulunan nrf24L01 ise alıcı olarak programlanmıştır. Bu durumda yalnızca santralden alıcılara doğru bir veri akışı söz konusu olmaktadır. Santral ile kablosuz akıllı kitler arasındaki veri alışverişi birbiriyle uyumlu olacak şekilde yazılımları yazılmıştır. Bunun yanında santralde yalnızca Bluetooth tarafından veri alacak şekilde yazılımı gerçekleştirilmiştir. Santral ve kablosuz akıllı kitler ayrı ayrı bir bütün oluşturacak şekilde tasarlanmış olup yazılımı sisteme özgü tasarlanmıştır.

Geliştirmiş olduğumuz Kablosuz Akıllı Kit, akıllı ev otomasyonu üzerine tasarlanmıştır. Sisteme verilen isim her ne kadar kablosuz akıllı kit olsa da temel de bir santral ve bu santrale bağlı birimler yönlendirilmektedir. Geliştirmiş olduğumuz akılllı ev otomasyonu geleneksel ev otomasyonlarından çok yönlü kullanımı ile ayrılmaktadır. Sistem tamamen hibrit olarak tasarlanmış olup hem kablolu sistemleri hem de kablosuz sistemleri kumanda edebilmektedir. Kontrol cihazına yüklediğimiz uygulama ile Bluetooth teknolojisinden yararlanılarak santral ile bağlantı sağlanmaktadır. Bu durumda herhangi bir ağ sistemine ihtiyaç duymadan santrale veri iletilmektedir. Sistemde tasarlanan portatif özellikli kablosuz akıllı kitler kumanda edilmek istenen aydınlatma ve elektronik cihazlara takıldığından ihtiyacınız kadar kullanabilir ve sistemden tasarruf sağlayabilirsiniz. Kablosuz akıllı kitler ile santral arasında ki veri alışverişi tamamen kablosuz iletişim sistemleri ile yapıldığından sistem kurulumu için herhangi bir alt yapıya ihtiyaç duyulmamaktadır. Hibrit olarak geliştirilen sistem aynı zamanda altyapısı mevcut olan yapılara da entegre edilebilmektedir. Kontrol cihazından gelen verilere bağlı olarak devreye alınan cihazlar santral üzerinde bulunan ledlerin yanmasıyla kullanıcı ile paylaşılmaktadır. Benzer şekilde santral üzerinde bulunan LCD ekran ile anlık durum bilgisi kullanıcılarla paylaşılmaktadır.

Geliştirmiş olduğumuz sistem kuvvetli akımın kumanda sisteminde kullanıldığı gibi zayıf akım üzerinde de kullanılabilmektedir. Sisteme özgü tasarlanan alarm sistemi ile evimizin güvenliğini üst seviyeye çıkarabiliriz. Sisteme entegre edilen pır sensörü alarm sisteminin devreye girmesiyle santrale, hareketin olup olmadığı bilgisini vermektedir. Eğer Pır sensörün kurulduğu bölgede herhangi bir hareket algılanırsa sensör santrale hareketin olduğuna dair sinyal göndererek santral de bulunan ikaz sisteminin devreye girmesini sağlamaktadır. Herhangi bir ikaz durumunda LCD ekrandan alarm bilgisi kullanıcılarla paylaşılıp santral üzerinde bulunan buton veya kontrol cihazı üzerinden alarm pasifleştirilebilmektedir.

Güvenlik sisteminin daha da geliştirilmesi üzerine sisteme eklenen keyped yapıya ait dış kapıya monte edilebilmektedir. Dış kapıya gelen kullanıcıların doğru şifreyi girmesi durumunda santrale komut gönderilmektedir. Santral ise gelen bu komuta bağlı olarak dış kapının açılmasını sağlamaktadır. Eğer şifre yanış girilmişse kullanıcıdan tekrar doğru şifrenin girilmesi istenmektedir.

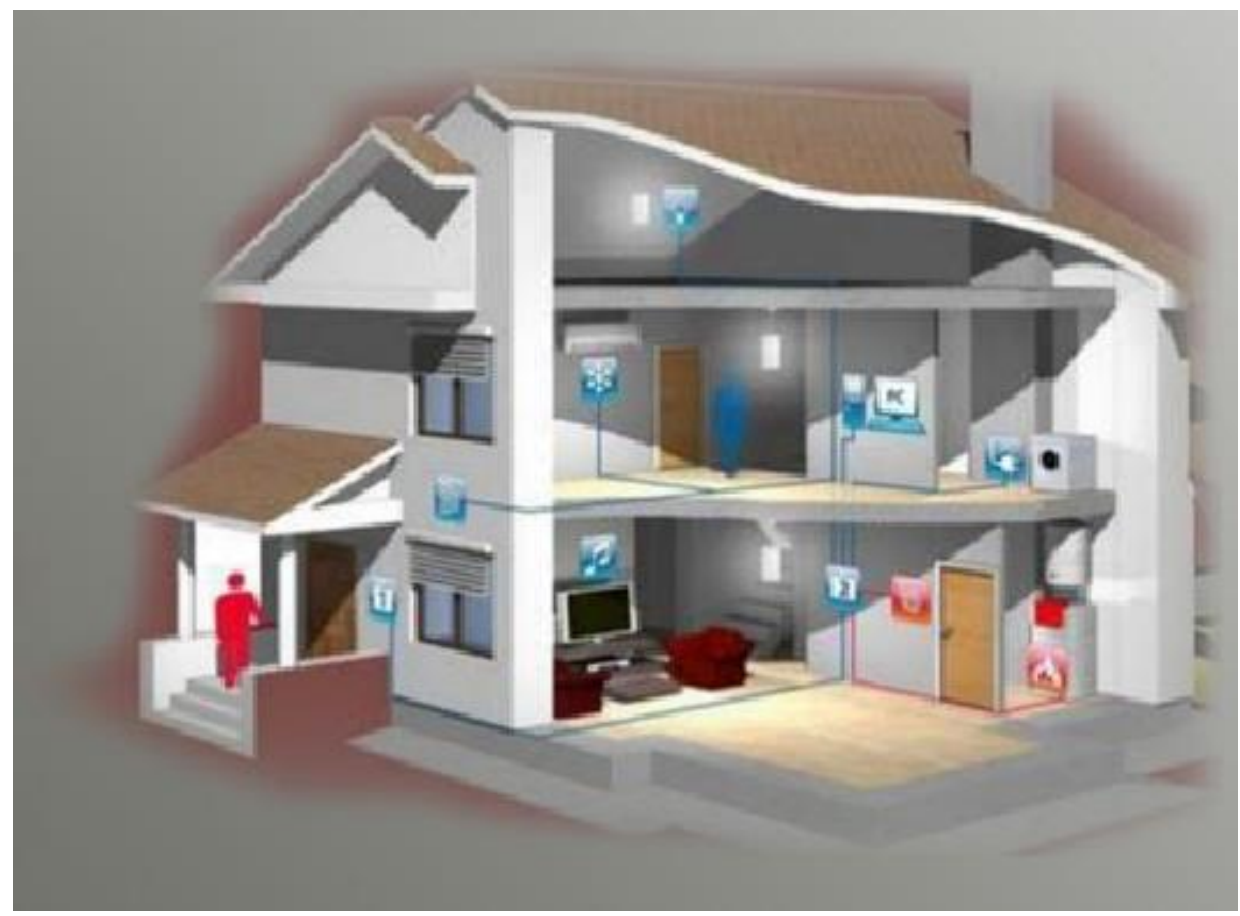

Şekil 5. Akill ev otomasyonuna ait görsel [14] 


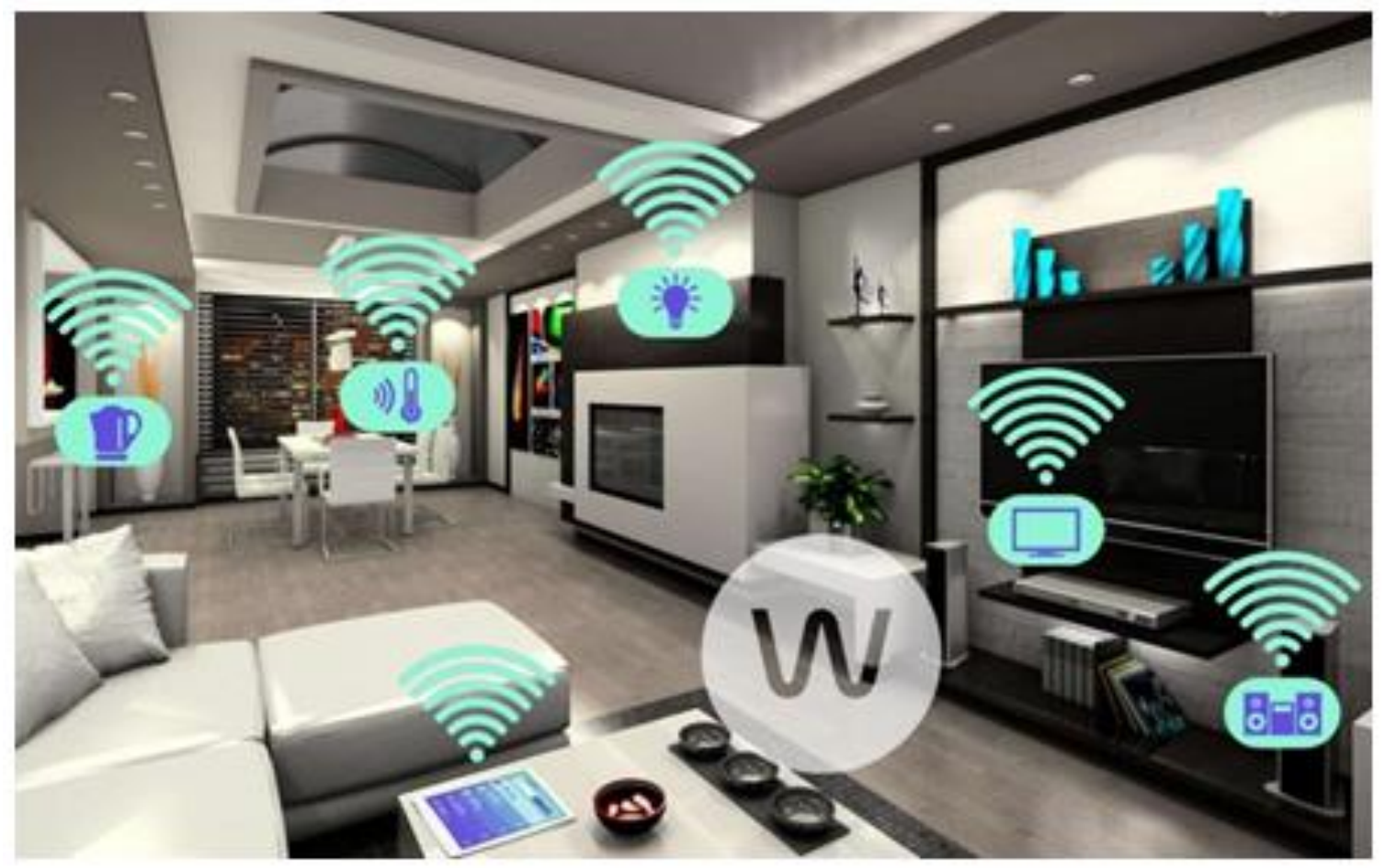

Şekil 6. Akullı kitin çallşmasına ait görsel [15]

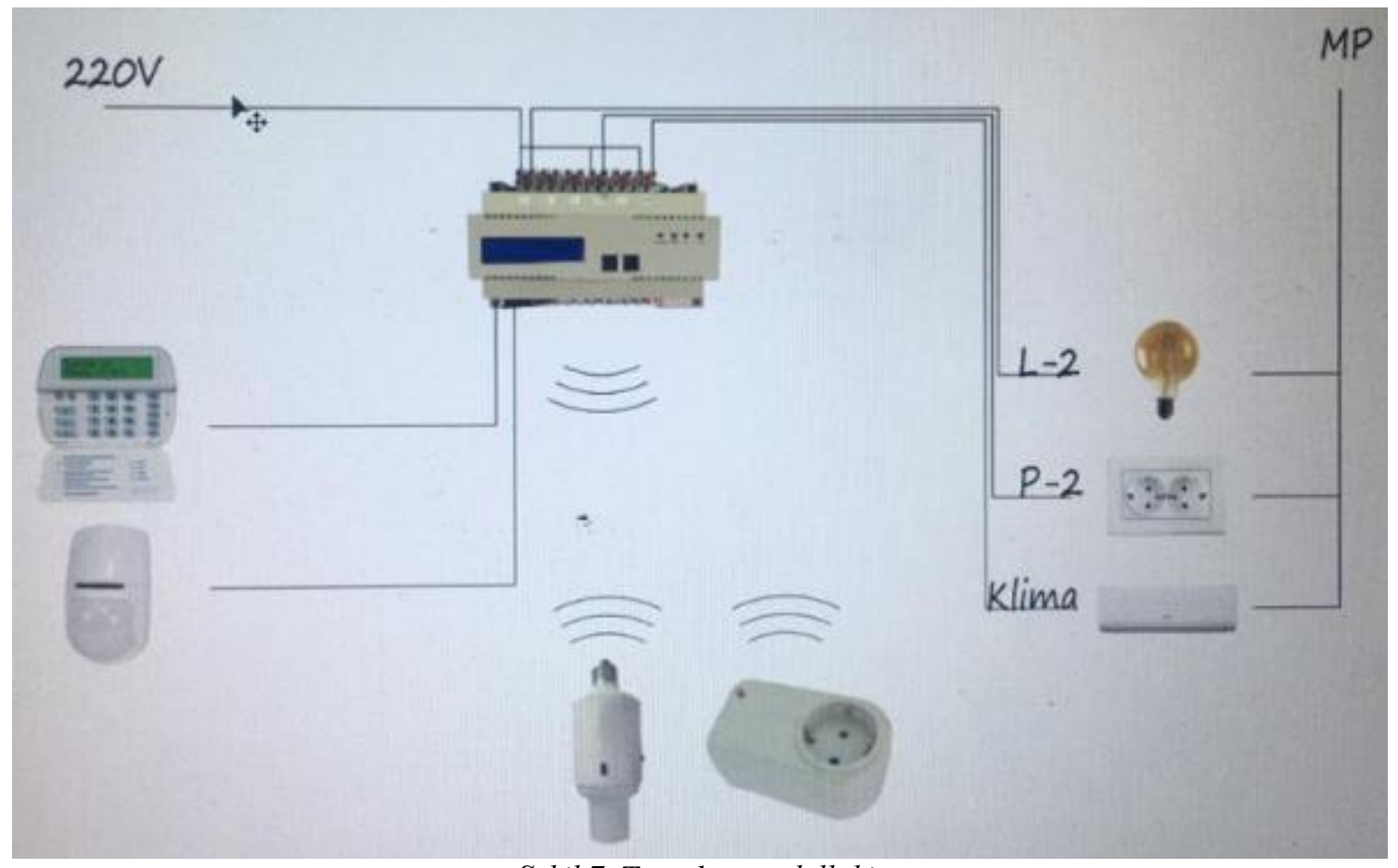

Şekil 7. Tasarlanan akıllı kit 

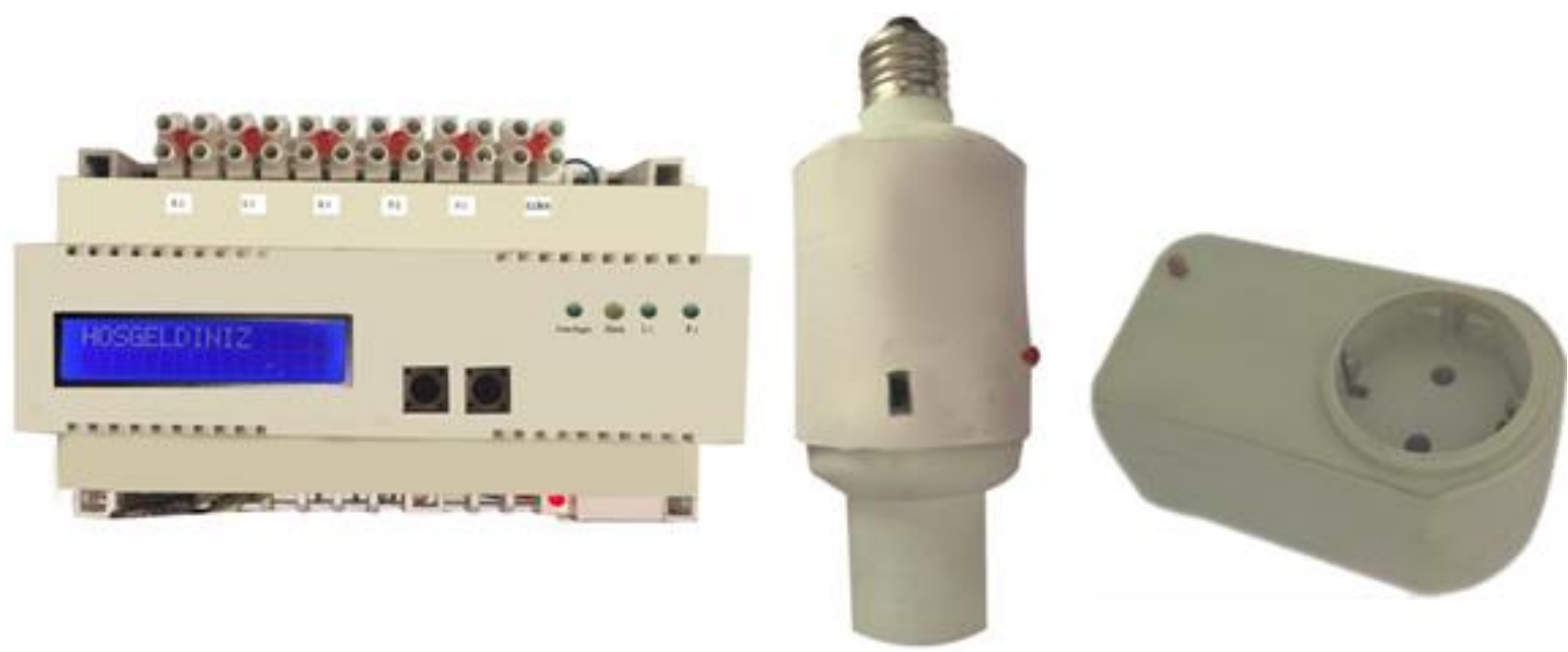

Şekil 8. Prototip olarak üretilen akıllı kit sistemi ve ekipmanlar

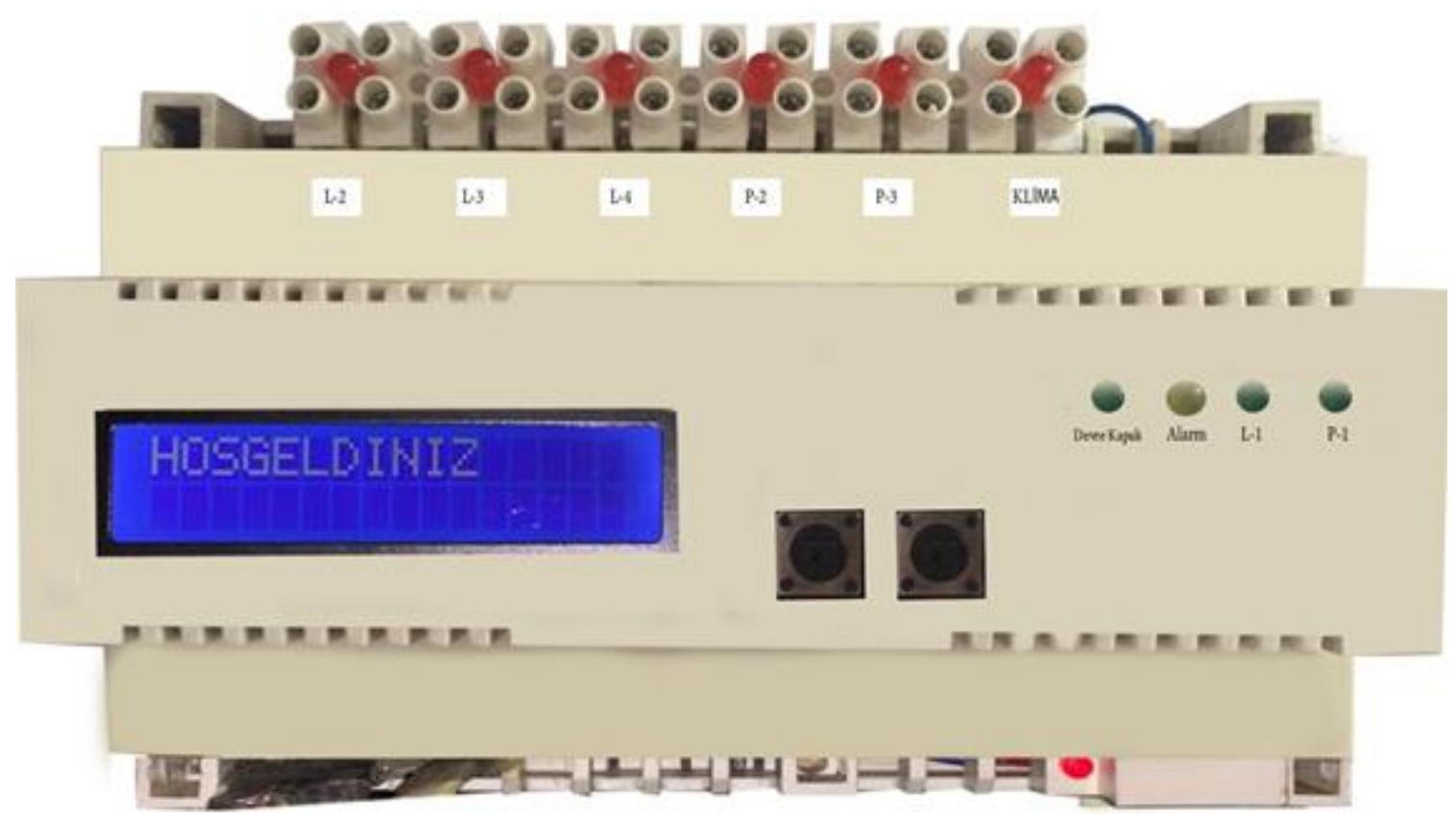

Şekil 9. Prototip olarak üretilen akıllı kit sistemi

Bu çalı̧̧mada tasarlanan ve imal edilen prototip akıllı kit sistemi Şekil 8 ve Şekil 9'da gözükmektedir.

\section{Sonuçlar ve Tartışma}

Akıllı ev otomasyonu gelişen teknolojinin bir ürünüdür. Günümüzde bir çok yeni yapıya entegre edilip elektrik enerjisinden tasarruf, güvenlik düzeyinin arttırılması ve yaşam standartlarının artmasına olanak sağlamaktadır. Mevcut akıllı ev sistemlerinin yapılara entegre edilmesi için yeni bir alt yapı çalışması gerekmektir üstelik bu oldukça maliyetlidir. Ayrıca sistemin kurulabilmesi için yeni bir alt yapı oluşturulmalıdır. Bu durumda sistemin kurulacağı yapıda alt yapının oluşturulması ile ekstra tadilat ve dekorasyon masrafları oluşmaktadır. Kullanıcı, enerji tasarrufu sağlamak ve güvenlik sistemini arttırmak istese de sistemin oldukça maliyetli olduğunu düşünerek geri çekilmektedir. Yeni oluşan yapılarda sistem alt yapısı kurularak akıllı ev otomasyonuna sahip olmaktadır. Ancak akıllı ev otomasyonunun zorunlu hale gelmesiyle mevcut yapıların tamamının dönüşümünün yapılması gerekecektir. Mevcut akıllı ev otomasyonlarının sisteme entegre edilmesi için gereken kablolu alt yapı oluşturulmalıdır. Bu yeni yapılacak yapılarda sürecin başında ve yapının, alt yapıyı kurmaya müsait olmasıyla sağlanabilir. Ancak mevcut yapılarda bu alt yapıyı oluşturmak oldukça maliyetlidir. Kablosuz akıllı kit ile veri iletimi, kablosuz iletişim modülleri kullanılarak gerçekleştirilmektedir. Böylelikle akıllı ev otomasyonuna geçecek yapılar için alt yapı oluşturulmayacak bundan kaynaklanan tadilat ve dekorasyon masrafları da ortaya çıkmayacaktır. Kablosuz akıllı kit ile bu dönüşümleri en az masraf ve alt yapıya gerek kalmadan tamamen kablosuz iletişim sistemiyle uzaktan kontrol edecek sistem kurulabilir. Böylece tüketicinin, akıllı ev otomasyonuna talebi arttırılmış ve akıllı ev otomasyonu, oldukça ekonomik bir şekilde sisteme entegre edilmiş olur. Bu çalışmada üretilen prototip kablosuz akıllı kit sistemi ile yapmak istediğimiz mevcut yapıların, akıllı ev otomasyonuna dönüşümünü kolaylaştırarak en az maliyet 
ile sağlamaktır. Tasarlanan kitler aydınlatma ve priz kitleri olmak üzere iki ana kit olarak üretilmesi planlanmıştır. İki ayrı kit üretilmesinin sebebi; prizlerin aydınlatmalara göre daha fazla güç çekmesidir. Bu durumda priz kitlerinde kullanılacak olan röleler, aydınlatma kitlerine göre daha fazla akıma dayanıklı olmalıdır. Kurulacak olan sistemde tüm kontrol ve komutların oluşturulacağı bir santrale yer verilecektir. Kitler ile santral arasındaki veri iletimi tamamen kablosuz iletişim kullanılarak yapılacaktır. Kitler ile santral kablosuz veri alışverişi yapabildiği gibi kontrol cihazları da (telefon, ipad, notebook vb.) santral ile kablosuz olarak veri alışverişinde bulunacaktır. Sistemde bulunan santral, yapının (evin) dağıtım kutusuna montajı yapılıp, sistemde bulunan tüm kitler ile kablosuz olarak iletişime geçecektir. Sistemde kurulacak olan kitler ise uzaktan kontrol edilmek istenen aydınlatma ve priz sortilerine montajı yapılacaktır. Örneğin evinizde bulunan klima hattına, kablosuz akıllı priz kitinin montajı yapıldı̆̆ını varsayalım. Bu durumda yerinizden bile kalkmadan veya dünyanın neresinde bulunursanız bunulun tek tuş ile klimanızı çalış̧ırabilirsiniz. Benzer şekilde evinizdeki aydınlatmalara, kablosuz aydınlatma kitinin montajı yapıldı̆̆ını varsayalım. Yine istediğiniz noktadan tek tuş ile aydınlatmalarınızı kontrol edebilirsiniz. Sistemde kullanılmak üzere tasarlanan kablosuz akıllı kitler uzak kumanda sistemine entegre olduğu gibi üzerinde bulunan (on-off) tuşu ile santralle bağlantısını kesip manuel olarak kullanılabilecektir. Kablosuz akıllı aydınlatma kitlerinin montajının yapıldığı aydınlatmalar manuel olarak anahtardan aç-kapa yapabildiğiniz gibi kontrol cihazlarınızdan da (telefon, bilgisayar, ipad vb.) açma ve kapama işlemi sürdürülebilecektir. Kablosuz akıllı kitler ekstra bir güç kaynağına gerek duymadan üzerine takılacak olan 9V pil ile enerji ihtiyacını karşılayacaktır. Tüm bu sistemler veri iletimini internet üzerinden kontrol cihazlarına aktarabildiği gibi evin içindeyken de radyo frekansları kullanılarak oldukça yüksek çekim alanında kontrol yapılabilir. Sistem her ne kadar ev için tasarlanmış olsa da uzaktan bir kontrol mekanizması oluşturulduğundan farklı alanlarda da kurulum yapılabilir.

Geliştirilen kablosuz akıllı kit hibrit özelliğe sahip olup hem kablolu sistemlerde hem de kablosuz olarak evimizdeki cihazları kontrol edebilme yeteneğine sahiptir. Kablosuz akıllı kitin şimdiye kadar bahsedilen fonksiyonlarının yanı sıra eklenmesi planlanan birçok sistem mevcuttur. İlerleyen aşamalarda kablosuz akıllı kitlerin yalnızca kontrol cihazı üzerinden değil de priz kitlerinin kendi üzerinde bulunan bir buton veya aydınlatma kitlerinin aydınlatma anahtarından kontrol edilebilme özelliği sisteme entegre edilebilir. Benzer şekilde daha önceden evinizde kullanmış olduğunuz akıllı ev otomasyonunun arızası durumunda farklı bir ürün olarak kendi sisteminize entegre edilebilir özelliği eklenebilir. Sistem kontrolü, bluetooth modülü üzerinden yapılabildiği gibi sistemin bağlı olduğu Wi-Fi üzerinden de yapılabilir. Bu durumda sistem kontrolü için yalnızca evin sınırlarında kalmayıp dünyanın her yerinden internet ağı yardımıyla sistem kontrolünü sağlayabilirsiniz. Santral üzerinde yapılan tüm işlem bilgisi anlık olarak LCD ekran üzerinden kullanıcı ile paylaşıldığı gibi kontrol cihazına da durum bilgisi anlık olarak aktarılabilir. Tüm bunların yanında sistemin kurulduğu yapının güvenlik sistemi elemanları kablosuz olarak tasarlanıp sinyaller kablosuz olarak santrale aktarılabilir. Bahçe sulama sistemi, yangın sistemi gibi sitemler akıllı ev otomasyonu bünyesine katılıp geliştirilebilir. Tüm bunların yanında akıllı ev otomasyonuna kişisel olarak hazırladığınız senaryolarınızı kaydedebilir, evinizde olmadığınız zamanlarda evdeymiş hissi vererek dış tehditlere karşı koruma sağlayabilirsiniz. Tasarlanan prototipler daha da küçültülüp kullanılabilirlik ve estetik tasarımı iyileştirilebilir.

Çalışmanın ilerleyen akademik ve sanayi çalışmalarında geliştirilmeye açık bir sistem olduğu düşünülmektedir. Bu çalışma kapsamında yapılan çalışmalar tamamlanmış olup prototip hazırlanmıştır. Hazırlanan prototip mevcut bir yapı içinde bulunan aydınlatma ve priz hatlarına takılıp testi sağlanmıştır. Test sonucuna göre $150 \mathrm{~m}^{2}$ ile $200 \mathrm{~m}^{2}$ arasında ki bir evde kablosuz akıllı kit ile santral arasındaki veri iletimi sorunsuz olarak sağlanmaktadır. Açık alanda ise $150 \mathrm{~m}$ ile $200 \mathrm{~m}$ arasında bir çekim gücü ile veri iletimi sağlanmaktadır. Benzer şekilde sistemin hibrit olma özelliği ile kablolu sistemlere de entegre edilip test edilmiştir. Her iki durumda da test sonuçları başarılı bir şekilde gerçekleştirilmiş olup kullanılır duruma getirilmiş̧ir. Sistemde bulunan güvenlik sistemlerinden alarm sistemi de testlerden başarıyla geçmiştir. Kapalı alanda $10 \mathrm{~m}^{2}$ alan içinde tek bir pır sensörden hareket bilgisi santrale aktarılabilmektedir. Gelen bilgiye göre santral ikaz verip kullanıcıya uyarı mesajı vermektedir. Giriş kapılarını açmak için sisteme eklenen keyped ise bağlı bulunduğu kapı devresini doğru şifrenin girilmesi durumunda açmış olup kontrol cihazı ile santral arasındaki bağlantı yaklaşık $25 \mathrm{~m}$ boyunca korunabilmektedir.

Genel olarak akıllı ev otomasyonunun istenilen ve uygulanılan fonksiyonlarının tamamının uygun şekilde çalıştığı gözlenmiştir. Bundan sonraki süreçte kablosuz akıllı kitlerden oluşan hibrit bir sistem olan akı1lı ev otomasyonunun geleceğini tasarlamaya ve daha iyi bir sistem oluşturmak için çalışmaların devam ettirilmesi hedeflenmektedir.

Ayrıca kablosuz akıllı kit oldukça ekonomik olarak tüketiciye ulaşmış olması hedeflenmektedir. Sistem kullanımı ve kurulumu bakımından oldukça kolay olup herkes tarafindan mevcut sisteme montajı yapılabilecektir. Bu çalışmada üretilen prototip kablosuz akıllı kit ile mevcut yapılara akıllı ev otomasyonunu, en az maliyet ile entegre edip bu sisteme karşı talebi arttıracak bir ürün olması düşünülmektedir. Benzer şekilde enerji israfının, kablosuz akıllı kitin sisteme entegre edilmesi ile önleneceği bir diğer amaç olarak ifade edilebilir.

Bu çalışma kapsamında geliştirilen kablosuz akıllı kit ile akıllı ev teknolojisinin mevcut fonksiyonlarının yanında daha birçok fonksiyon eklenebilir ve sistemin kullanılabilirliği arttırılabilir. Bu yönüyle geliştirilmeye oldukça açık bir sistem olmaktadır. Kablosuz akıllı kit çalışmasının ülkemiz için yeni gelir kapısı ve yeni yatırım merkezlerinin kurulmasına fayda sağlaması da ayrı bir amaç olarak ifade edilebilir.

\section{Teşekkür}

Bu makalenin yazarları, verilen destekten dolayı Siirt Üniversitesi Otomasyon ve Kontrol Sistemleri Laboratuvar çalışanlarına teşekkür ederler. 


\section{Kaynakça}

[1] Suh, C., \& Ko, Y. B. (2008). Design and implementation of intelligent home control systems based on active sensor networks. IEEE Transactions on Consumer Electronics, 54(3), 1177-1184.

[2] David, A. B. (2013). U.S. Patent No. 8, 527, 278. Washington, DC: U.S. Patent and Trademark Office.

[3] Sixsmith, A. J. (2000). An evaluation of an intelligent home monitoring system. Journal of telemedicine and telecare, 6(2), 63-72.

[4] Stefanov, D. H., Bien, Z., \& Bang, W. C. (2004). The smart house for older persons and persons with physical disabilities: structure, technology arrangements, and perspectives. IEEE transactions on neural systems and rehabilitation engineering, 12(2), 228-250.

[5 ]Douligeris, C. (1993). Intelligent home systems. IEEE Communications Magazine, 31(10), 52-61.

[6] Bayram, U. (2006). Akıllı Ev Otomasyonu, Çanakkale Onsekiz Mart Üniversitesi, Fen Bilimleri Enstitüsü, Yüksek Lisans Tezi Bilgisayar Bölümü, Bilgisayar Anabilim Dalı.

[7] Cincirop, B. (2009). GSM Kontrollü Akıllı Ev Otomasyonu, Sakarya Üniversitesi, Fen Bilimleri Enstitüsü, Yüksek Lisans Tezi.

[8] Ali, M. Q. (2018). Akıllı ev otomasyonu için güvenlik kamerası ve bulanık mantık tabanlı yangın algılama ve söndürme sistemi tasarımı ve gerçekleştirilmesi, Selçuk Üniversitesi Fen Bilimleri Enstitüsü, Yüksek Lisans Tezi.

[9] Kongaz, H. (2007). Akıllı Ev Otomasyonunun Mikrodenetleyici ile Gerçekleştirilmesi, , Yıldız Teknik Üniversitesi, Fen Bilimleri Enstitüsü, Yüksek Lisans Tezi.

[10] Robles, R. J., \& Kim, T. H. (2010). Applications, systems and methods in smart home technology: A. Int. Journal of Advanced Science And Technology, 15.

[11] Zhou, B., Li, W., Chan, K. W., Cao, Y., Kuang, Y., Liu, X., \& Wang, X. (2016). Smart home energy management systems: Concept, configurations, and scheduling strategies. Renewable and Sustainable Energy Reviews, 61, 30-40.

[12] Çubukçu, A., Kuncan, M., Kaplan, K., \& Ertunc, H. M. (2015, May). Development of a voice-controlled home automation using Zigbee module. IEEE in 2015 23nd Signal Processing and Communications Applications Conference (SIU) (pp. 1801-1804).

[13] Han, D. M., \& Lim, J. H. (2010). Design and implementation of smart home energy management systems based on zigbee. IEEE Transactions on Consumer Electronics, 56(3), 1417-1425.

[14] https://onedio.com/haber/kariyerinize-dogru-yon-verin-gelecegi-insa-edecek-yarinlarin-5-teknik-meslegi-740036, (ziyaret tarihi: $01.10 .2019)$

[15] https://www.xenonsmart.com/neden-akilli-ev-almaliyim/, (ziyaret tarihi: 01.10.2019) 